\title{
Prevalence and predictors of episiotomy and perineal tear at a tertiary hospital in Port-Harcourt, Nigeria
}

\author{
Peter A. Awoyesuku*, Dickson H. John, Basil O. Altraide
}

Department of Obstetrics and Gynaecology, Rivers State University Teaching Hospital, Port-Harcourt, Nigeria

Received: 08 September 2020

Accepted: 08 October 2020

\section{*Correspondence:}

Dr. Peter A. Awoyesuku,

E-mail: pawoyesuku@yahoo.co.uk

Copyright: (C) the author(s), publisher and licensee Medip Academy. This is an open-access article distributed under the terms of the Creative Commons Attribution Non-Commercial License, which permits unrestricted non-commercial use, distribution, and reproduction in any medium, provided the original work is properly cited.

\begin{abstract}
Background: Despite many years of it being practiced, episiotomy has remained a controversial operation. The rate is on the decline in developed countries but remains high in developing countries. This study seeks to determine the prevalence of episiotomy and perineal tear, and to assess the associated factors, at the Rivers state university teaching hospital (RSUTH).

Methods: A retrospective study over a two-year period, from 01 January 2018 to 31 December 2019, was carried out. All women who had singleton spontaneous vaginal deliveries (SVD) with episiotomy or perineal tear at the RSUTH with complete records were included, those with twin delivery and incomplete data were excluded. Data was retrieved from the birth registers and case notes using a proforma. Information on maternal age, parity, gestational age (GA), type of injury, birth weight, head circumference and Apgar scores were extracted. Data were analyzed using statistical package for the social sciences (SPSS) version 20.

Results: There were 2150 vaginal deliveries, with 440 (20.5\%) receiving episiotomy, while 21 (1.0\%) had perineal tear. The mean age \pm standard deviation (SD) was $29.52 \pm 4.97$ years, median parity was 1 , and mean GA \pm SD was $37.35 \pm 1.71$ weeks. The mean birth weight \pm SD was $3.33 \pm 0.52 \mathrm{~kg}$ and mean head circumference \pm SD was $34.76 \pm 1.90$ $\mathrm{cm}$. There was significant association between maternal parity and fetal birth weight with the occurrence of episiotomy and perineal tears.

Conclusions: The rate of episiotomy and perineal tear was higher than recommended, with an increasing trend. The lower the parity and the higher the fetal birth weight, the likelihood to receive an episiotomy. More efforts are needed to reduce the rate.
\end{abstract}

Keywords: Episiotomy, Perineal tear, Prevalence, Predictors, Tertiary hospital

\section{INTRODUCTION}

Episiotomy is an intentional surgical incision made on the perineum with the aim of enlarging the pelvic outlet during childbirth. ${ }^{1}$ The procedure is usually administered for several reasons including to prevent severe perineal laceration or tear in the parturient, especially in the primigravidae. ${ }^{2}$ For the neonate, it is suggested that episiotomy reduces prolonged second stage in some cases of rigid perineum which could lead to fetal asphyxia, cranial trauma and cerebral haemorrhage. ${ }^{1}$ It is easier to repair and has better healing than perineal tears because it is a straight and clean incision.

The routine use of episiotomy results in high episiotomy rates where it is practiced, however the World Health Organization (WHO) recommends restrictive or selective use over routine use. ${ }^{3}$ Aiming surgically to cut all women delivering vaginally has no demonstrable benefit for infant or mother but causes the woman unnecessary pain and may be associated with potential short-term (pain, haemorrhage and infection) and long-term (dyspareunia, incontinence of flatus and faeces) complications. ${ }^{4}$ 
A policy of selective episiotomy has been in place in many Nigerian hospitals, including our hospital, and it is based only on individual midwife/doctor's decision, without a shared and uniform protocol and indications. Following evidence-based practices, only mediolateral technique is being used and the repair with an absorbable continuous locking suture being used to fix episiotomies and vaginal tears. 5,6

The reported rates of the procedure around the world ranges from as low as $9.7 \%$ in Sweden to $100 \%$ in Taiwan. ${ }^{7}$ In a sister tertiary hospital in Port-Harcourt, Nigeria, the rate has been reported as $39.1 \%$ in the year 2007, which is higher than the $10 \%$ recommended by the WHO. ${ }^{7-9}$ In nearby Calabar, a metropolitan city like Port Harcourt also in south-southern Nigeria, a recent study showed a comparatively low episiotomy rate of $20.1 \%$ among all women that had a vaginal delivery. ${ }^{10}$ In other parts of Nigeria, a study from Zaria reported a rate of $35.6 \%$ following all vaginal deliveries and $88.5 \%$ in primigravidae; in Enugu, the rate was $40.4 \%$ for all parities and $76.2 \%$ in primigravidae..$^{2,11}$

It has been known that perineal tears were observed in women that had not undergone episiotomy, which suggest episiotomy prevents unwanted tear. ${ }^{12}$ However, with the practice of the preferred selective or restrictive episiotomy, cases of perineal tear occur, which raises the issue of selection of cases for the application of episiotomy. This can only be resolved by a careful assessment of likely predictors for episiotomy need and its application in caseselection.

There is paucity of data on episiotomy and perineal tears in our environment. It is important to review the rate and obstetric predictors of episiotomy and perineal tear as such will guide towards more informed decision on its application and reduce the level of unnecessary interventions and episiotomies.

This study, therefore, seeks to determine the prevalence and rates of episiotomy and perineal tear in women delivering at the RSUTH and to assess the associated factors or predictors of being given an episiotomy at delivery. The findings of this study will help in caseselection for episiotomy, as it will assist in the development of a shared and uniform protocol and indications. This will help develop strategies towards reducing the high episiotomy rates in developing countries.

\section{METHODS}

This study was conducted at the labour ward of the RSUTH, a tertiary hospital owned and funded by the Government of Rivers State. Patients are expected to pay directly for services they receive (except few that participate in the national health insurance scheme). The hospital provides emergency obstetric services to women referred from other centers, as well as providing antenatal care and delivery services for low and high-risk pregnant women booked with the hospital. The hospital is well equipped and has availability of qualified team comprising of obstetricians, paediatricians and anaesthetists. There is availability of laboratory and blood bank services in the hospital. The labour ward is open 24 hours/7 days, and there is an average annual delivery of over 1000 women.

A retrospective descriptive study over a two-year period, from 01 January 2018 to 31 December 2019, was carried out. The study population were all pregnant women who had singleton spontaneous vaginal delivery (SVD) with episiotomy or perineal tear at the labour ward of the RSUTH. All singleton SVD cases receiving episiotomy or perineal tear over the study period with complete records were included. Those with twin delivery and incomplete data were excluded.

Data was retrieved from the hospital records (birth registers) and case notes of all the patients using a proforma data sheet. Information on maternal age, parity, gestational age, type of birth injury and birth weight, head circumference and Apgar scores of their babies were extracted.

Coded data were entered into excel spreadsheet and exported to statistical package for the social sciences (SPSS) version 20 for statistical analysis. Categorical measurements were given as numbers and percentages, and numerical measurements as mean and standard deviation (SD). Nonparametric (Mann-Whitney U) test, the chi-square and analysis of variance (ANOVA) (Fisher's) test were used, as appropriate, for statistical analysis and statistical significance was set at $\mathrm{p}<0.05$.

\section{RESULTS}

Over the two-year study period there were a total of 2150 SVDs; 1102 (51.3\% in 2018 and 1048 (48.7\%) in 2019. $440(20.5 \%)$ received an episiotomy and $21(1.0 \%)$ had a perineal tear (Figure 1). There was an increasing trend in the yearly rates from 2018 to 2019 (Table 1). The mean age of the women \pm SD was $29.52 \pm 4.97$ years, median age was 30 years and age range was 17-48 years. The median parity was para 1; range was para 1-6. The mean gestational age $(\mathrm{GA}) \pm \mathrm{SD}$ was $37.35 \pm 1.71$ weeks; the median was 37 weeks, with range of 30-43 weeks (Table 2). The demographic characteristics is as shown in Table 3.

The mean birth weight \pm SD of their babies was $3.33 \pm 0.52$ $\mathrm{kg}$ with median of $3.30 \mathrm{~kg}$ (range 1.20-5.10) and the mean head circumference \pm SD was $34.76 \pm 1.90 \mathrm{~cm}$ with median of 35 (range 27-43) as shown in Table 4 and 5.

An analysis of the associated factors revealed a statistically significant association between maternal parity $(\mathrm{p}=0.0001)$ and fetal birth weight $(\mathrm{p}=0.021)$ and the occurrence of episiotomy and perineal tears. The association with age $(\mathrm{p}=0.175)$, GA $(\mathrm{p}=0.480)$, Apgar 
score $(\mathrm{p}=0.057)$ and head circumference $(\mathrm{p}=0.103)$ were not statistically significant (Table 6). The lower the parity and the higher the fetal birth weight, the likelihood that a woman will receive an episiotomy.

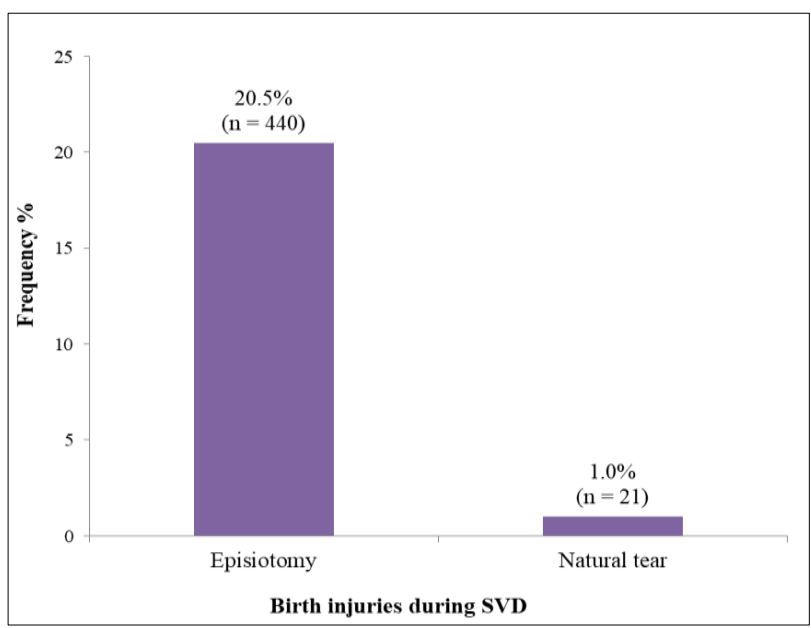

Figure 1: Prevalence of episiotomy and perineal tear among women during SVD at RSUTH.

Table 1: Trend of birth injuries among women at RSUTH over the two-year period.

\begin{tabular}{|llll|} 
Variable & $\begin{array}{l}\text { Episiotomy } \\
\mathbf{N}(\%)\end{array}$ & $\begin{array}{l}\text { Natural tear } \\
\text { N }(\%)\end{array}$ & $\begin{array}{l}\text { Total } \\
\mathbf{N}(\%)\end{array}$ \\
\hline $\mathbf{2 0 1 8}$ & $166(37.7)$ & $8(38.1)$ & $174(37.7)$ \\
\hline $\mathbf{2 0 1 9}$ & $274(62.3)$ & $13(61.9)$ & $287(62.3)$ \\
\hline Total & $440(100.0)$ & $21(100.0)$ & $461(100.0)$ \\
\hline
\end{tabular}

Chi square $=0.001, \mathrm{p}$ value $=0.973$

Table 2: Summary of age, parity, and GA at delivery of women with episiotomy and perineal tear at RSUTH.

\begin{tabular}{|lll|}
\hline Variables & Mean \pm SD & Median (range) \\
\hline Age in years & $29.52 \pm 4.97$ & $30(17-48)$ \\
\hline Parity & - & Para 1 (para 1-6) \\
\hline $\begin{array}{l}\text { GA at delivery } \\
\text { (weeks) }\end{array}$ & $37.35 \pm 1.71$ & $37(30-43)$ \\
\hline
\end{tabular}

SD-standard deviation, GA-gestational age
Table 3: Characteristics of women receiving episiotomy and perineal tear at RSUTH.

\begin{tabular}{|lll|}
\hline Variables $(\mathbf{N}=461)$ & Frequency & Percentage \\
\hline Age in years & & \\
\hline$<20$ & 12 & 2.6 \\
\hline $20-29$ & 213 & 46.2 \\
\hline $30-39$ & 231 & 50.1 \\
\hline$\geq 40$ & 5 & 1.1 \\
\hline Parity & \\
\hline Para 1 & 309 & 67.0 \\
\hline Para 2-4 & 147 & 31.9 \\
\hline Para $\geq 5$ & 5 & 1.1 \\
\hline Gestational age at delivery (weeks) & \\
\hline$\leq 36$ & 134 & 29.1 \\
\hline $36-40$ & 316 & 68.5 \\
\hline$>40$ & 11 & 2.4 \\
\hline
\end{tabular}

Table 4: Summary of birth weight and head circumference at birth of neonates of women with episiotomy and perineal tear at RSUTH.

\begin{tabular}{|lll|}
\hline Variables & Mean \pm SD & Median (range) \\
\hline Birth weight $(\mathbf{k g})$ & $3.33 \pm 0.52$ & $3.30(1.20-5.10)$ \\
\hline $\begin{array}{l}\text { Head circumference } \\
\text { (cm) }\end{array}$ & $34.76 \pm 1.90$ & $35(27-43)$ \\
\hline
\end{tabular}

SD-standard deviation

Table 5: Characteristics of neonates of women with episiotomy and perineal tear at RSUTH.

\begin{tabular}{|lll|}
\hline Variables* $(\mathbf{N}=461)$ & Frequency & Percentage \\
\hline Birth weight $(\mathbf{k g})$ & & \\
\hline$\leq 2.5$ & 27 & 5.9 \\
\hline $2.6-3.9$ & 388 & 84.2 \\
\hline$\geq 4.0$ & 46 & 10.0 \\
\hline Head circumference $(\mathbf{c m})$ & \\
\hline$<35$ & 186 & 40.3 \\
\hline $35-38$ & 272 & 59.0 \\
\hline$\geq 39$ & 3 & 0.7 \\
\hline APGAR score & & \\
\hline Poor $(<7)$ & 307 & 66.6 \\
\hline Good $(\geq 7)$ & 154 & 33.4 \\
\hline
\end{tabular}

Table 6: Factors associated with getting an episiotomy and perineal tear during delivery at RSUTH.

\begin{tabular}{|llll|}
\hline Variables & Episiotomy $\mathbf{N}=\mathbf{4 4 0}(\boldsymbol{\%})$ & Natural delivery $\mathbf{N}=\mathbf{2 1}(\boldsymbol{\%})$ & Total N=461 $(\boldsymbol{\%})$ \\
\hline Age in years & & & $12(100.0)$ \\
\hline$<20$ & $12(100.0)$ & $0(0.0)$ & $213(100.0)$ \\
\hline $20-29$ & $206(96.7)$ & $7(3.3)$ & $231(100.0)$ \\
\hline $30-39$ & $218(94.4)$ & $13(5.6)$ & $5(100.0)$ \\
\hline$\geq 40$ & $4(80.0)$ & & \\
\hline Fisher's exact test=4.308; p value=0.175 & $5(1.6)$ & $309(100.0)$ \\
\hline Parity & $304(98.4)$ & $12(8.2)$ & $147(100.0)$ \\
\hline Para 1 & $135(91.8)$ & $4(80.0)$ & $5(100.0)$ \\
\hline Para 2-4 & $1(20.0)$ & & \\
\hline Para $\geq 5$ & & & \\
\hline
\end{tabular}

Continued. 


\begin{tabular}{|c|c|c|c|}
\hline Variables & Episiotomy N=440 (\%) & Natural delivery $\mathbf{N}=21$ (\%) & Total N=461 (\%) \\
\hline & \multicolumn{3}{|c|}{ Fisher's exact test $=32.527 ; \mathrm{p}$ value $=0.0001^{*}$} \\
\hline \multicolumn{4}{|c|}{$\begin{array}{l}\text { Gestational age at delivery } \\
\text { (weeks) }\end{array}$} \\
\hline$\leq 36$ & $130(97.0)$ & $4(3.0)$ & $134(100.0)$ \\
\hline $36-40$ & $300(94.9)$ & $16(5.1)$ & $316(100.0)$ \\
\hline$>40$ & $10(90.9)$ & $1(9.1)$ & $11(100.0)$ \\
\hline & \multicolumn{3}{|c|}{ Chi square $=1.468 ; p$ value $=0.480$} \\
\hline \multicolumn{4}{|c|}{ Fetal birth weight $(\mathbf{k g})$} \\
\hline$\leq 2.5$ & $27(100.0)$ & $0(0.0)$ & $27(100.0)$ \\
\hline $2.6-3.9$ & $373(96.1)$ & $15(3.9)$ & $388(100.0)$ \\
\hline$\geq 4.0$ & $40(87.0)$ & $6(13.0)$ & $46(100.0)$ \\
\hline & \multicolumn{3}{|c|}{ Fisher's exact test $=6.972 ; \mathrm{p}$ value $=0.021^{*}$} \\
\hline \multicolumn{4}{|c|}{ Fetal head circumference $(\mathbf{c m})$} \\
\hline$<35.0$ & $182(97.8)$ & $4(2.2)$ & $186(100.0)$ \\
\hline $35.0-38.0$ & $255(93.8)$ & $17(6.2)$ & $272(100.0)$ \\
\hline$\geq 39.0$ & $3(100.0)$ & $0(0.0)$ & $3(100.0)$ \\
\hline & \multicolumn{3}{|c|}{ Fisher's exact test $=4.765 ; \mathrm{p}$ value $=0.103$} \\
\hline \multicolumn{4}{|c|}{ APGAR score outcome } \\
\hline Poor & $289(94.1)$ & $18(5.9)$ & $307(100.0)$ \\
\hline Good & $151(98.1)$ & $3(1.9)$ & $154(100.0)$ \\
\hline
\end{tabular}

*Statistically significant $(\mathrm{p}<0.05)$

A comparison between episiotomy versus perineal tear revealed a statistically significant association with mean age $(\mathrm{p}=0.019)$, median parity $(\mathrm{p}=0.001)$ and mean birth weight $(\mathrm{P}=0.0004)$. Older women, of higher parity, and higher fetal birth weights were more likely to have a perineal tear than receive an episiotomy. The association with mean GA ( $\mathrm{p}=0.317)$ and mean head circumference were however not statistically significant (Table 7 and 8 ).

Table 7: Comparison of mean age, gestational age at delivery and median parity by prevalence of episiotomy and perineal tear among women delivering at RSUTH.

\begin{tabular}{|lllll|}
\hline Variable & Episiotomy, mean \pm SD & Natural tear, mean \pm SD & $\mathbf{t}$ & P value \\
\hline Age in years & $29.40 \pm 4.97$ & $32.00 \pm 4.18$ & -2.358 & $0.019^{*}$ \\
\hline Gestational age at delivery & $37.33 \pm 1.73$ & $37.71 \pm 1.27$ & -1.001 & 0.317 \\
\hline Variable & Median (range) & Median (range) & Mann-Whitney U & P value \\
\hline Parity & $1(1-6)$ & $2(1-6)$ & 2123.500 & $0.0001^{*}$ \\
\hline
\end{tabular}

*Statistically significant, SD-standard deviation

Table 8: Comparison of mean fetal birth weight and head circumference by prevalence of episiotomy and perineal tear among women delivering at RSUTH.

\begin{tabular}{|lllll|}
\hline Variable & Episiotomy, mean \pm SD & Natural tear, mean \pm SD & $\mathbf{t}$ & P value \\
\hline Birth weight $(\mathbf{k g})$ & $3.31 \pm 0.52$ & $3.65 \pm 0.47$ & -2.881 & $0.004^{*}$ \\
\hline Head circumference $(\mathbf{c m})$ & $34.73 \pm 1.91$ & $35.38 \pm 1.40$ & -1.529 & 0.127 \\
\hline
\end{tabular}

*Statistically significant, SD-standard deviation

\section{DISCUSSION}

The rate of episiotomy in this study of $20.5 \%$ was like the findings of the more recent study from Calabar, a metropolitan city like Port Harcourt also in south-southern Nigeria, of $20.1 \% .^{10}$ The rate in this study is lower than a similar study from the same Port Harcourt city of $39.1 \%$ in 2000, and other studies across Nigeria as reported in Benin $46.6 \%$ in 2000 , Lagos $54.9 \%$ in 2002 , Zaria $35.6 \%$ in 2003, Enugu 40.4\% in 2004 and Abia 45\% in 2008., $, 8,11,13-$ ${ }^{15}$ The difference may be attributed to the fact that over time, there has been increased emphasis on restrictive rather than routine use of episiotomy in line with evidencebased recommendations. ${ }^{1}$ However, this decline in the rate of episiotomy is still higher than the $10 \%$ recommended by WHO, which calls for continuous restraint by those who conduct deliveries if the rates in developing countries are to reduce. ${ }^{9}$ Perineal tear occurred in $1.0 \%$ of the study population, perineal tears were observed in women that had not undergone episiotomy, which suggest episiotomy prevents unwanted tear. ${ }^{12}$ Despite the practice of the preferred selective or restrictive use of episiotomy, cases 
of perineal tear still occurred, which raises the issue of selection of cases for the application of episiotomy.

This study also identified maternal parity and fetal birth weight as significant risk factors that increased the risk of episiotomy in the study population. The lower the parity and the higher the fetal birth weight, the likelihood that a woman will receive an episiotomy. This finding agrees with studies by Izuka et al and Hembah-Hilekaan et al. ${ }^{16,17}$ Women of lower parity, especially nullipara, are thought to have more firm and tense perineal muscles leading to a higher likelihood for episiotomy and tears. Larger fetal weight may lead to an actual or perceived threat of perineal tear.

Maternal age, GA at delivery, head circumference and Apgar score were not significant in their association. Hembah-Hilekaan et al however found a significant association with younger maternal age, as well as parity, and rate of episiotomy. ${ }^{17}$ The difference may lie in the study population, with parity being the common denominator. The mean age of mothers in this study of 30 years is higher than other studies which had a higher adolescent population while the median parity is 1 . Izuka et al also found an association with GA at delivery, this is related to fetal weight which increases with GA. ${ }^{16}$

The study also revealed that older women, of higher parity, and higher fetal birth weights were more likely to have a perineal tear than receive an episiotomy. Women of higher parity essentially are considered to have a much lax perineum and often considered not to require an episiotomy, without regards for the estimated fetal weights (EFW). The result is often perineal tear and calls for a better patient selection that considers the EFW.

The limitation of this study is the retrospective nature, with its inherent limitations and weaknesses, for instance data on the occupation, educational status and physical stature of the mothers were difficult to retrieve because of inadequate record keeping.

\section{CONCLUSION}

The rate of episiotomy and perineal tear was higher than recommended, with an increasing trend. The lower the parity and the higher the fetal birth weight, the likelihood that a woman will receive an episiotomy. Older women, of higher parity, and higher fetal birth weights were more likely to have a perineal tear than receive an episiotomy. More efforts are needed to reduce the rate and reverse the trend.

\section{ACKNOWLEDGMENTS}

The authors would like to acknowledge the contributions of the interns and resident doctors who voluntarily assisted in the extraction of data from the birth registers and case notes.
Funding: No funding sources

Conflict of interest: None declared

Ethical approval: The study was approved by the Institutional Ethics Committee

\section{REFERENCES}

1. Carroli G, Mignini I. Episiotomy for vaginal birth. Cochrane Database Syst Rev. 2009;1:CD000081.

2. Onah HE, Akani CI. Rates and predictors of episiotomy in Nigerian women. Trop J Obstet Gynaecol. 2004;21:44-5.

3. World Health Organization (WHO). Appropriate technology for birth. Lancet. 1985;2(8452):436-7.

4. Maduma-Butshe A, Dyall A, Garner P. Routine episiotomy in developing countries: Time to change a harmful practice. BMJ. 1998;316(7139):1179-80.

5. Kettle C, Dowswell T, Ismael KM. Continuous and interrupted suturing techniques for repair of episiotomy or second-degree tears. Cochrane Database Syst Rev. 2012; 11(11):CD000947.

6. Kettle C, Dowswell T, Ismael KM. Absorbable suture materials for primary repair of episiotomy and second-degree tears. Cochrane Database Syst Rev. 2010;2010(6):CD000006.

7. Graham ID, Carroli G, Davies C, Medves JM. Episiotomy rates around the world: An update. Birth 2005; 32: 219-23.

8. Enyindah CE, Fiebai PO, Anya SE, Okpani AO. Episiotomy and perineal trauma prevalence and obstetric risk factors in Port Harcourt, Nigeria. Niger J Med. 2007;16(3):242-5.

9. World Health Organization (WHO). Care in normal birth, a practical guide [serial on the internet]. 1996. Available at: http://www.who.int/making-pregnancysafer/document/who-frh-msm-9624/en/. Accessed on: 26 July 2020.

10. Inyang-Etoh $\mathrm{CE}$, Umoiyoho AJ. The practice of episiotomy in a university teaching hospital in Nigeria. Int J Med Biomed Res. 2012;1:68-72.

11. Sule ST, Shittu SO. Puerperal complications of episiotomies at Ahmadu Bello University Teaching Hospital, Zaria, Nigeria. East Afr. Med J. 2003;80:351-6.

12. Ekwempu CC. Maternal injuries. In: Agboola A. ed. Textbook of Obstetrics and Gynaecology for Medical Students. Ibadan: Heinemann Educational Book Plc. 2006; $477-80$.

13. Otoide VO, Ogbonmwan SM, Okonofua FE. Episiotomy in Nigeria. Int $\mathbf{J}$ Gynaecol Obstet. 2000;68(1):13-7.

14. Ola ER, Bello O, Abudu OO, Anorlu RI. Episiotomies in Nigeria - should their use be restricted? Niger Postgrad Med J. 2002;9(1):13-6.

15. Chigbu B, Onwere S, Aluka C, Kamanu C, Adibe E. Factors influencing the use of episiotomy during vaginal delivery in South-Eastern Nigeria. East Afr Med J. 2008;85(5):240-3.

16. Izuka EO, Dim CC, Chigbu CO, Obiora-Izuka CE. Prevalence and predictors of episiotomy among 
women at first birth in Enugu, South-East Nigeria. Ann Med Health Sci Res. 2014;4:928-32.

17. Hembah-Hilekaan SK, Ojabo OA, Audu O, Onche PE, Maanongun MT. Prevalence of episiotomy and perineal lacerations in a University Teaching Hospital, North-Central Nigeria. J Biomed Res Clin Pract. 2018;1(2):142-7.
Cite this article as: Awoyesuku PA, John DH, Altraide BO. Prevalence and predictors of episiotomy and perineal tear at a tertiary hospital in PortHarcourt, Nigeria. Int J Reprod Contracept Obstet Gynecol 2020;9:4595-600. 